\title{
Porotic hyperostosis and the Gelligaer skull
}

\author{
JOHN CULE AND I. LYNN EVANS
}

SYNOPSIS The differential diagnosis of the bony lesions known as porotic hyperostosis found on a Bronze Age child's skull is discussed. Keith and Shattock gave an opinion in 1923 that the cause was rickets. A firm conclusion is not reached in this paper, but it is suggested that it was more likely to have been an iron-deficiency anaemia.

\section{HISTORY OF THE SKULL}

In 1923 Dr R. E. M. Wheeler, who subsequently became Director of the National Museum of Wales, quoted Sir Arthur Keith's reasons for believing that he had been able to diagnose rickets in the skull of a Bronze Age child.

'The antiquity of this skull becomes very important for this reason: on the forehead you will see two patches of inflammatory bone, which my colleague, Professor Shattock, says are typical "Parrot's nodes." These are always the result either of syphilis or of rickets, in this case rickets. The diagnosis is confirmed by the condition seen in the unerupted upper lateral incisor tooth, which shows marks or constrictions resulting from two attacks, one occurring when the child was about six months of age, and the second about six months later. You will notice that areas of inflammatory bone or nodes, due to rickets, occur on the hinder part of the skull also. If the teeth had not been present we should have suspected syphilis. . . .'

The skull had been discovered in a stone cist in the farmyard of Llancaiach Isaf (map reference 19 SE:154:115962). Mr George Seaborne reopened the cist on 25 June 1901 and reported in the Western Mail of 19 July 1901 that the grave was 'of oblong shape, $2 \mathrm{ft} 6 \mathrm{in}$. long, $1 \mathrm{ft} 9$ in. wide, $1 \mathrm{ft} 2$ in. deep from the surface of the ground, and is covered with a large rough stone, the sides and ends being formed by flat stones standing on edge. When first opened the grave contained a vase, or urn, partly full of black mould or ashes, and a human skull, both being nearly perfect at that time. The skull is now broken, and the fragments are contained in the vase, which is also broken'.

In 1923, the cist, beaker, and skull were removed to the National Museum of Wales where they are now classified (NMW. 22 149/1-3).

Received for publication 3 January 1968.
The beaker has been described by $\operatorname{Dr} \mathrm{H}$. W. Savory 'as very well fired thick ware with rosy buff surface. Decorated with incisions and stabbed dots in groups of seven'. The dimensions reported were 10.2 in. in height and mouth diameter 5.9 in. (Savory, 1955). The beaker is of the debased South Wales ' $C$ ' type, and in a personal communication Dr Savory suggested that its probable date lay between the limits of 1650 and 1550 B.C. There seems to be no reason to doubt the association of the skull with the beaker.

The area in which the find was made is of flaggy sandstones of the upper coal measures series (personal communication, D. Emlyn Williams, Assistant Keeper, Geology, National Museum of Wales). These are low in calcium. The low calcium content of the sandstone and the prolonged effect of the Welsh rainfall would tend to reduce the calcium content of bone buried for some 3,000 years. The position of the cist at the edge of the farmyard and near the entrance to the cowshed would have exposed the bones to contamination with bovine urine over a period of at least 50 years. This would not have affected the calcium level, as the very low urinary calcium of the lactating cow would be insufficient either to raise or even maintain the calcium content of the bony remains.

\section{MACROSCOPICAL ANATOMY}

The skull is now in a very fragmented condition and it has been possible only partially to restore its contours. Sufficient remains to show the pathological nodes and the dental changes remarked upon by Keith and Shattock.

\section{DIMENSIONS}

Maximum cranial length (L) Maximum cranial breadth (B)

Frontal eminence to occiput
$145 \mathrm{~mm}$ $140 \mathrm{~mm}$ $145 \mathrm{~mm}$ 
Forehead width (glabellar suture to anterior zygomatic tubercle) (cf Brothwell, 1963a) $92 \mathrm{~mm}$ BONE THICKNESS

Nasion (total thickness)

Midway between nasion and bregma

Bregma

Vertex

Lambda

R Euryon

The figures in the second column are for mean bone thicknesses of male white North American children aged 6 years (Roche, 1953).

The dental age of the Gelligaer skull was assessed from the teeth described below, which were the only ones remaining at the time of our examination in 1966.

A portion of the upper jaw contains an U.R. 6 permanent (first molar). The unworn surface of the first permanent molar is visible in the specimen. Anterior to it is a broken crypt containing a portion of the developing second permanent premolar. There is an empty crypt for the first permanent premolar, with a portion of the permanent canine showing in its anterosuperior wall. This was confirmed radiologically. There are also empty crypts for the permanent lateral and central incisors.

Another portion of the upper jaw contains an U.L. 6 permanent (first molar). The unworn surface of the first permanent molar is visible in the specimen and has a similar morphology to that of U.R. 6. Anteriorly is a broken empty crypt for the second permanent premolar, and then an empty crypt for the first permanent premolar. In its anterosuperior wall the L. permanent canine is exposed, split longitudinally and the enamel divided horizontally by two grooves (Fig. 1, cf Keith and Shattock). Anteromedially lies the empty crypt for the permanent central incisor; that for the lateral incisor seems to be missing.

There are also five teeth not attached to the jaw: an upper left deciduous canine with a broken root; a deciduous central incisor (probably U.L.) with very little worn enamel and no root absorption; a deciduous molar with four tubercles and two roots, one fused, which is probably U.R. deciduous molar 2; an unerupted permanent molar with an unformed root, no wear but damaged crown enamel showing originally five tubercles, probably L.R. 6 permanent (first molar); and an upper right permanent incisor, unerupted which fits into the crypt in the portion of the right jaw. This last incisor shows two deep horizontal grooves in the enamel (Fig. 2). The dentition suggests the development of a child of 6 years (Brothwell, 1963b). It will be seen from the

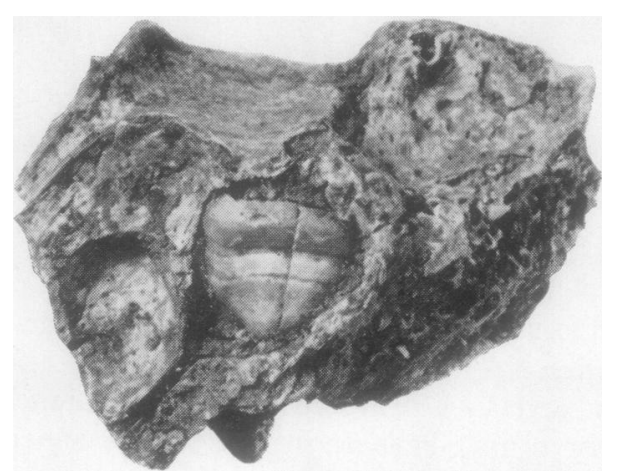

FIG. 1. Left upper permanent canine tooth, enlarged $\times 2$

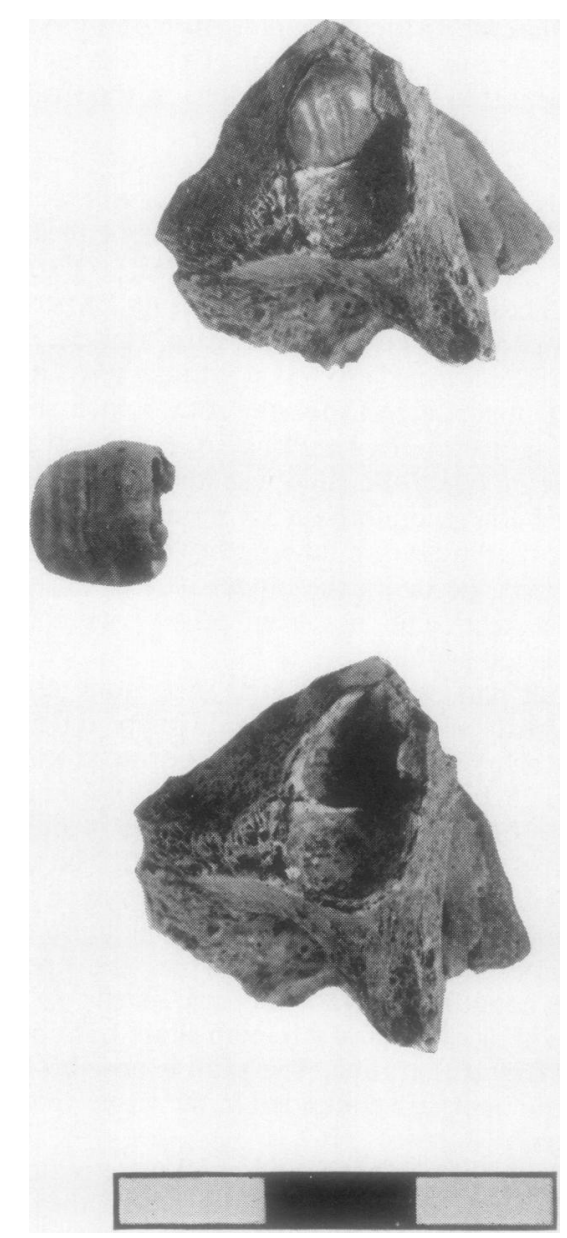

FIG. 2. Right upper permanent incisor tooth. 




FIG. 3. Enlarged view of right frontal node. (Photographs for Figs. 1, 2, and 3 by the Wellcome Medical Museum and Library.)

cranial measurements that the bone thickness of the Gelligaer skull is greater than that of the average recorded by Roche (1953) for a comparable modern skull.

The frontal bossing of the Gelligaer skull is not symmetrical in that the right node is nearer the midline and higher than the left one. They are both clearly above the frontal eminences. The macroscopic appearances are clearly shown in Figure 3.

\section{MICROSCOPICAL ANATOMY}

Dr J. Ball of the University of Manchester kindly reported on sections of the skull. These were not cut from the porotic areas, which proved too brittle at the edges of existing fragments of skull for satisfactory specimens to be obtained.

MACROSCOPIC APPEARANCE The specimen is a thin $(1.5 \mathrm{~mm})$, slightly curved plate of homogeneous brittle material the colour of yellow ochre.

MICROSCOPIC APPEARANCE The first piece was sectioned without decalcification. In such preparations bone mineral is normally uniformly distributed. In this Llancaiach Isaf skull fragment the mineral is in the form of closely packed calcospherites orientated in linear arrays corresponding to birefringent strands which probably represent the remains of the organic matrix. Haversian systems cannot be definitely identified. A probable explanation of these findings is that the skull fragment has been partially demineralized after death.

A second piece showed inner and outer tables with intervening cancellous, which appeared healthy.

After embedding a specimen in acrylic, sections were prepared for electron microscopy. The illustrations (Figs. 4a and b) show a photograph of a ground, unstained section, and a microradiograph of a ground section at a higher magnification. These show normal bone. The absence of any excess of unmineralized bone excludes a diagnosis of either rickets or osteomalacia. The lack of osteoid seams might indicate a cessation of bone growth, but this might possibly be a feature of this selected specimen only.

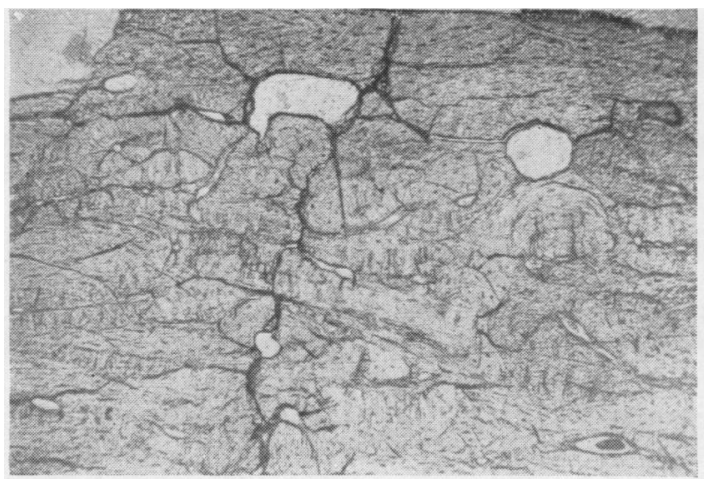

FIG. 4a.

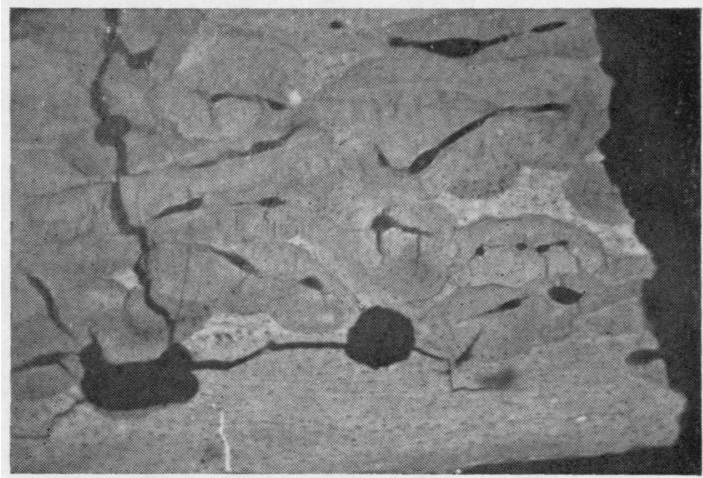

FIG. $4 b$.

FIG. 4. (a) Ground unstained section, approximately $\times$ 100; (b) microradiograph of ground section, approximately $\times 100$. (Reproduced by the courtesy of $\mathrm{Dr} \mathrm{J}$. Ball, Rheumatism Research Laboratories, University of Manchester.)

\section{DISCUSSION}

The asymmetry of the bossing suggests a metabolic change in a skull which may also have been distorted by excessive moulding at birth. This appearance provides no evidence either in support or refutation of a diagnosis of rickets. The multiplicity of bosses and their bilateral distribution makes sepsis or 




FIG. 5. Sagittal radiograph of skull. (Reproduced by the courtesy of Mr Don Brothwell, British Museum, Natural History.)

wounding an unlikely cause. Such lesions have been noted frequently in recent years in Palaeolithic skulls. Although they do not appear to be reported from modern necropsy rooms in Britain, McKern and Stewart (1957) mention cranial 'osteoporosis' in some Korean war dead. The proliferative macroscopic appearances are quite strikingly different from those of the normal skull and cannot be regarded as artefactual. The condition has been called porotic hyperostosis or 'osteoporosis symmetrica', and in a recent paper Angel (1964) has suggested that the change could have been caused by thalassaemia.

The morphological appearance of porotic hyperostosis is essentially that of the diploic thickening present in the severe anaemias of childhood. In these there has been compensatory overgrowth of marrow in the skull diploe which at first may both displace and thin the outer table, eventually breaking through it in places to continue its proliferation subperiosteally. At the same time new bone spicules are laid down at right angles to the surface giving the characteristic 'hairbrush' radiological appearance (Fig. 5).

In thalassaemia major there are other skeletal changes beside those in the calvarium. The diploic widening first evident in the frontal bones and the orbits is accompanied by enlargement of the facial bones, particularly the maxillae, leading to the development of mongoloid features. The rodent facies due to the central incisors being displaced and the malocclusion of the jaw is also a stigma of this haemoglobinopathy. The paranasal sinuses and the mastoid air cells cannot contain air. The red marrow of the skeleton undergoes hyperplasia with widening of the medullary cavities and thinning of the bone cortices, and the shafts of both the long. and the short tubular bones may become osteo $\Rightarrow$ porotic. Other bone contours may be destroyed? (Moseley, 1966). These changes are most marked in? thalassaemia major and less so in thalassaemia minor.

In sickle cell anaemia the appearance of the skulp is that of thalassaemia major but without the alterees facies and there is also less marked skeletal change $\overrightarrow{0}$ In hereditary spherocytosis, with its more moderateanaemia, there is even less bony dysplasia. Diploiow thickening of the calvarium may be found in severe? iron-deficiency anaemia in childhood, but the faciapo and skeletal changes are absent (Lie Injo Luan Rng, 1958).

के

Hamperl and Weiss (1955) discuss other possiblevt differential diagnoses, and cite Parrot (1879) on syphilis which Keith felt had been excluded on the evidence of the teeth in the Gelligaer skull. They $\vec{z}$ also cite Hooton (1930), who on examining the skullso of 21 children aged between 6 and 12 years, found\$ that 14 showed the changes of hyperostosis porotica. 3 There was no evidence of rickets in the remaining $\stackrel{\mathbb{Q}}{-}$ bony skeletons. Letterer (1949) has attempted to $\vec{\circ}$ delineate the differences between rickets in childhood, showing osteoid tissue hypertrophy beside the sutures, osseous rather than marrow thickening of the diploe and lack of boss remodelling, with the changes shown in the anaemias. Both have to be distinguished from the effects of haematomaectocranial or epidural. ${ }^{1}$

The condition of hyperostosis porotica seen in $\overrightarrow{\vec{O}}$ ancient skulls was first described by Hrdlička (1914) as 'symmetric osteoporosis', and he gives credit to Virchow (1874) for an earlier description. Williams (1929) made some original observations $\overline{0}$ on 'symmetrical osteoporosis', and in 1934 Müller:made the suggestion that 'hyperostosis spongiosa' would be a better name for the condition. The $\delta$ condition of hyperostosis porotica must now be $₹$ regarded as a result of hyperplasia of the erythro- 0 poietic tissue of the skull, sometimes accompanied? by erythropoietic hyperplasia of other tissue such as long bone marrow, in the course of severe anaemias. A useful review of the literature on hyper- $\sigma$ ostosis porotica is given by Jarcho (1966).

A firm diagnosis of the illness of the Gelligaer child $N$ is precluded by the amount of material available for $\sigma$ study. One cannot tell if the pathological changes in these small remnants were part of the disease responsible for death. Apart from the partially $\stackrel{\oplus}{\oplus}$ reconstructed calvarium, the teeth, and a portion of the facial bones nothing else remains but a fragment $\overline{0}$ of long bone measuring $48 \mathrm{~mm}$ in length which $\stackrel{\mathbb{D}}{\Omega}$ might possibly be from femur and another of $22 \mathrm{~mm} \approx$ ${ }^{1}$ We are indebted to Dr J. L. Angel for this information and reference. 
which might possibly be tibia. The absence of bowing in the long bone fragments is slight evidence against the presence of rickets. None of the air sinuses nor any part of the mastoid process remains. From a study of this scant material a severe anaemia (probably due to iron deficiency) seems the most likely diagnosis. There is not sufficient evidence to exclude thalassaemia with complete certainty.

Further speculation on the cause of the anaemia is tempting. An iron-deficiency anaemia may be found in association with dietetic deficiency; it is easy to imagine this possibility in a Bronze Age child living in the Glamorgan hills. The family may have been part of a very small population of the new agriculturalists. Cereals and small apples were already cultivated in Britain (Helbaek, 1952). The pig Sus scrofula and the cow Bos longifrons were already domesticated (Fox, 1952). Hunted deer may have added to the available protein. Animal food was probably adequate to supply the small amount of iron needed to maintain the normal iron balance of male adults. The problem might well have been more acute in growing children born of women whose iron reserve may have been depleted, particularly if there had been food shortages during the pregnancy. The Bronze Age child may have started life with an iron deficiency. Infants require a positive iron balance over and above that necessary for normal iron metabolism. Additional iron is needed for the increasing amount of haemoglobin in the increasing blood volume and also to cover the increasing bulk of such organs as the liver, spleen, bone marrow, etc. Winter deficiency of vitamins (particularly vitamin C) would impair iron absorption. Intercurrent infection (demonstrated in the Gelligaer child by the tooth grooving) might cause anaemia even if adequate iron were available. These Bronze Age folk did not even have the advantage of using rusty iron instruments to increase their iron intake (Keele and Neil, 1965). Iron-deficiency anaemia must have been a common cause of ill health.

The possibility of a genetically transmitted anaemia such as thalassaemia (Mediterranean anaemia or Cooley's anaemia) being the cause of bony change in a British skull opens up at first sight exciting concepts of being able to confirm population movements from the Mediterranean basin. This, however, does not seem so probable on a closer examination of the distribution of the disease. It has a world-wide distribution: there is a high incidence in the Mediterranean countries and also in southeast Asia, but it has also been recorded in China, the Philippines, Australia, New Guinea, Africa, and the West Indies. Of course, Englishmen and Americans may also show the disease; in global distribution thalassaemia is the most widely spread haemoglobinopathic disorder known (Chatterjea, 1965).

There is another feature of the thalassaemia carrier which merits attention from the palaeopathologist. This concerns the problem of how such a high gene frequency producing the disease can be maintained despite the early deaths of the homozygotes before they are old enough to transmit the gene to their offspring. It is apparently not due to a highly exaggerated mutation phenomenon maintaining a supply of heterozygote and it has been suggested that there is a compensatory protection for the heterozygote against malaria and possibly against other infections as well as against iron deficiency (Chatterjea, 1965).

Angel (1964) speculates on osteoporosis and thalassaemia in a recent paper and writes the thalassaemic heterozygote ... shows enough resistance to malaria so that thalassaemia is classed as polymorphism and is increased in frequency in areas of past endemic malaria. . . .

\section{ALPHA ACTIVITY OF THE GELLIGAER SKULL}

It would be of value to palaeopathologists to find a method of dating material which was both less destructive and less costly than by measurement of carbon 14. In an attempt to confirm the historical age of the specimen we submitted portions of the skull and the beaker to Dr R. C. Turner for his comments on the radium-226 content. Unfortunately contamination of the specimens since their burial had nullified the value of the results in estimating their ages by this method.

The natural radium content of present-day human bone can be measured provided one has either a specimen of 1 or $2 \mathrm{~g}$ which can be reduced to mineral ash or, alternatively, a piece of skull, for instance, with an area of 8 to 10 square centimetres. In the latter case the specimen can be measured without being sacrificed. Since the radioactive half-life of radium-226 is approximately 1,600 years, the level of activity in bone 3,000 or so years old would be expected to be less than one quarter of the value in present-day specimens. Such activity is near the limit of measurement even with extremely sensitive modern techniques and a specimen of the order of the size indicated.

The alpha activity of a portion of the skull was found to be 50 or more times higher than expected and there is little doubt that this resulted from contamination of the specimen by soil and soil liquids. This was borne out by the evident presence of the thorium series of radioelements which are not found in human bones which are older than 100 years or so. The estimated present radioactivity of 
this specimen was therefore no indication of the activity of the actual bone itself.

The alpha activity of the pottery material and its thorium content were also both typical of soils. The older the soil the higher in general will be the thorium/ uranium ratio, since the radioactive half-life of thorium-232 is so much longer than that of uranium-238. Very old Cambrian rock specimens have $\mathrm{Th} / \mathrm{U}$ ratios as high as four or five to one, for instance. The pottery material is evidently very much younger and its absolute activity and its $\mathrm{Th} / \mathrm{U}$ ratio are very similar to the values observed in a number of Welsh soils and in sand specimens from the Isle of Wight.

The results confirmed our suspicions that measurements of alpha activity in bones contaminated by soil and soil liquids cannot be used as simple guides to their age. Specimens on which radium-226 estimations are to be made should be selected very carefully and stored immediately in polythene bags. Particular care should also be taken to avoid tobacco ash coming into contact with them and automatic lighters and flints should be kept out of the immediate vicinity.

We should like to thank Dr H. N. Savory, Keeper of the Department of Archaeology, National Museum of Wales, for his generosity in allowing us to study the Gelligaer material, and Mr G. C. Boon, the Assistant Keeper, for his assistance during the preparation of this paper. Mr D. Lloyd Griffiths, of the Department of Orthopaedic Surgery, and Dr John Ball, of the Department of Pathology at the University of Manchester, have given us useful advice on the pathology of bone, as has Dr R. C. Turner of the Department of Physics at the Institute of Cancer Research on the problems of its alpha activity. Mr H. V. Cockburn helped with the problems of age and dentition. The Wellcome Historical Medical Museum and Library kindly photographed the specimens and the Wellcome Trustees supported the work of John Cule with a gran toward his expenses on research in the history of medicine in Wales during the time this paper was written. The South East Metropolitan Regional Board grante I. Lynn Evans two days' study leave for research Cardiff.

Mr Don Brothwell of the British Museum (Naturoक्ष History), Dr J. L. Angel of the Smithsonian Institution. and Dr A. T. Sandison of the Pathology Departmen?, University of Glasgow, have answered our queries enabling us to profit from their original researches in the్ branch of palaeopathology.

\section{REFERENCES}

Angel, J. L. (1964). Amer. J. phys. Anthrop. (n.s.), 22, 369. Brothwell, D. R. (1963a). Digging up Bones, p. 79. British Museufg (Natural History), London. (1963b). Ibid., p. 59 (Fig. 24).

Chatterjea, J. B. (1965). Triangle (En.), 7, p. 101.

Fox, C (1952). The Personality of Britain, 4 th ed. National Museum of Wales, Cardiff.

Hamperl, H., and Weiss, P. (1955). Virchows Arch. path. Anat., 32 629.

Helbaek, H. (1952). Proc. prehist. Soc., 18, 194.

Hooton, E. A. (1930). The Indians of Pecos Pueblo: a Study of The Skeletal Remains. Yale University Press, New York.

Hrdlicka, A. (1914). Smithson misc. Collns, 61, 57.

Jarcho, S., ed. (1966). Human Palaeopathology. Yale University Prese New Haven and London.

Keele, C. A., and Neil, E., eds. (1965). Samson Wright's Applige Physiology, 11 th ed., p. 82. Oxford University Press, Londono

Letterer, E. (1949). Zbl. allg. Path. path. Anat., 85, 244.

Lie Injo Luan Rng. (1958). Acta haemat. (Basel), 19, 263.

McKern, T. W., and Stewart, T. D. (1957). Skeletal Age Changes Young American Males. (Technical Report, U.S. Quartef master Research and Development Command.) U.S.Q.R.D.CD Natick, Mass.

Moseley, J. E. (1966). In Human Palaeopathology, edited by S. Jarch $\vec{g}$ p. 121. Yale University Press, New Haven and London.

Müller, H. (1934). Geneesk. T. Ned.-Ind., 74, 1084.

Parrot, J. (1879). Trans. path. Soc. Lond., 30, 339.

Roche, A. F. (1953). Hum. Biol., $25,81$.

Savory, H. N. (1955). Bull. Bd Celt. Stud., 16, 236.

Virchow, R. (1874). Verh. berl. Ges. Anthrop., 6, 51.

Wheeler, R. E. M. (1923). Antiquaries J., 3, 21.

Williams, H. U. (1929). Arch. Path., 7, 839. 